\title{
Development of a specialized topographic map of environmental protection using the example of bog massifs
}

\author{
T.V. Vereshchaka ${ }^{\text {a, }}{ }^{*}$, I.E. Kurbatova ${ }^{\text {b,c }}$, A.A. Ivanova ${ }^{\text {d }}$, A.L. Stepanchenko ${ }^{\text {e }}$ \\ ${ }^{a}$ Moscow State University of Geodesy and Cartography, Moscow, Russia, cartography@miigaik.ru \\ ${ }^{b}$ Moscow State University of Geodesy and Cartography, Moscow, Russia, irenkurb@yandex.ru \\ ${ }^{c}$ Water Problems Institute of Russian Academy of Sciences, Moscow, Russia, irenkurb@yandex.ru \\ ${ }^{d}$ Moscow State University of Geodesy and Cartography, Moscow, Russia, ania.ivanova96@yandex.ru \\ e Moscow State University of Geodesy and Cartography, Moscow, Russia, stalex@miigaik.ru \\ * Corresponding author
}

Keywords: bogs, peat extraction lands, disturbed ecosystem, satellite imagery, specialized topographic map

\begin{abstract}
:
Specialized topographic maps of land or water areas are maps created on the basis of universal topographic maps within the limits of their accuracy and in a single technological cycle with them, with the addition of content or its directed unloading for a specific area of use (while maintaining an image of a complex of main topographic objects). These maps are targeted at specific consumer groups.
\end{abstract}

Specialized topographic maps have taken a firm place in the cartographic information support of various fields of application as a result of the organizational restructuring of topographic surveys and state topographic mapping. The main arguments for the restructuring and its optimization were, on the one hand, the possibility of producing specialized maps in a single technological cycle with the universal ones (provided that the most expensive work is performed once), as well as the elimination of duplication, fragmentation of work performance by organizations that do not own modern technologies and trained specialists of the required qualification level. On the other hand, the demand for this type of maps is increasing, since the demands of science and practice have determined the needs for topographic maps of land and water areas, which go beyond the content of universal maps for multipurpose purposes and the solution of only navigation problems.

Together with universal topographic maps, specialized ones represent the basis of the state cartographic fund of the country, the federal fund of spatial data and its basic component - a unified electronic cartographic basis. Specialized mapping has received great development both in Russia and in foreign countries. An analysis of maps and developments based on them shows that the practical experience and directions of research on the problem in Russia are quite consistent with international trends in mapping.

At the initial stage, the provision of requests with specialized maps, both in Russia and abroad, related to the sectors of the economy - land reclamation, agriculture, forestry, geological exploration, mining and oil refining, geophysical research, industrial urban and rural construction, linear construction (railways and highways, trunk pipelines, communication and power lines). With the beginning of topographic surveys of the shelf of the seas and inland water bodies, the need for the creation of specialized maps of water areas was also revealed.

In recent years, information support for the environmental safety of various spheres of society, inventory of natural resources, monitoring of natural and anthropogenic processes, prevention of critical and catastrophic situations has been added to the topical areas of using both domestic and foreign maps. Such information contributes to the harmonization of nature-society relations and, ultimately, ensures the sustainable development of territories.

The demand for specialized maps as a reliable comprehensive information base is increasing over time. New tasks are being set that oblige to expand and improve this direction. One of the directions is not only the study and satisfaction of object-oriented requirements for maps, but also the development of scientifically based types of specialized topographic maps. Our research is devoted to the development of an ecologically oriented type of maps, where the object of mapping is bogs.

Specialization of bog massif maps can be carried out in the following areas:

- displaying of individual biosphere functions (hydrological, biological, resource);

- displaying the internal structure and specifics of landscapes and microlandscapes of raised and back bogs;

- displaying of the consequences of economic activity (irreversible and partial transformations of landscapes);

- displaying of the undisturbed natural state of bog ecosystems of various degrees of protection regime (with the allocation of the location of especially valuable areas). 
Let us point out the priorities for displaying bog landscapes on the created specialized topographic maps, which could ensure the geographical correspondence of the natural pattern of the area and its transformation as a result of economic activity. On the one hand: the degree of permeability, the depth of the peat layer, the internal structure of bogs (lines of drainage of seepage waters, areas of open water, lakes, forms of microrelief (hillocks, hummocks, ridges)); the status and boundaries of specially protected natural areas; observation points (amelioration-bog stations, integrated bog experimental and forest-reclamation stations, hydrometeorological posts). On the other hand: areas of industrial development; drainage channels and ditches; linear communications; areas of pollution (oil, etc.); places where untreated wastewater is discharged; depressed and disturbed vegetation, etc.

When developing a map, all topographic objects of the area and their characteristics that do not violate the type of universal topographic maps are displayed on the original of a specialized map, and not included in the current system of notation for topographic maps and contradicting its type are disclosed by compiling a text reference (geographical characteristics). The essence of such reference is to give more detailed information about the objects shown on the author's original map. The reference, in conjunction with the map, provides detailed information about the study area. The main information of the reference is a text with additions in the form of diagrams, tables, photographs, satellite images, inset maps.

The problem of studying and protecting bogs for Russia, as well as for a number of other countries, is urgent. In the world, the area of swamps occupies 5 million square kilometers and a third of this territory is located in Russia. Bog massifs are diverse in type, genesis, characteristics, conditions of formation, regional features.

The implementation of proposals for mapping bog massifs was carried out on the example of a developed type of specialized topographic map of a unique natural ecosystem, one of the largest in Europe, with an area of about 180 thousand hectares, formed at the beginning of the Holocene.

The concept of the map assumes the representation of the bog as an ecosystem, which, along with the natural state, experiences anthropogenic impacts in the form of peat extraction, demographic pressure, the influence of transport, fires and other processes associated with human life. The dynamics of landscapes and the results of anthropogenic impacts over a period of 50 years are traced. The consequences of carrying out reclamation measures after aggressive economic influence are revealed. A map of fires and smoke pollution in the adjacent territories has been compiled. When compiling the maps, methods of remote sensing and geoinformation technologies were used. The map and accompanying geographic information are illustrated in the report. In general, illustrations include:

1. Geographical location of the study area;

2. Author's original of the specialized topographic map of the bog massif;

3. Photo map of the internal structure of bog landscapes;

4. Dynamics of lakes within the protected area and peat extraction lands (period 1968 - 2018);

5. Dynamics of vegetation within the protected area and peat extraction lands (period $1968-2018$ );

6. Crop canopy condition after reclamation;

7. The image of indicators of the dynamics of objects on multitemporal space images and topographic maps of different years of publication;

8. Examples of using the normalized NDVI and NDWI indices for studying the dynamics of water bodies and crop canopy;

9. Map of fires, smoke and areas covered by fires.

The temporal coverage of the period of transformation of bog landscapes in several decades made it possible to differentiate the bog massif according to the ecological state after anthropogenic interference and to assess the ability of landscapes to restore. The obtained data can be used to monitor and predict further changes, assess the reversibility of disturbed landscapes, and to develop measures for the protection of wetlands in general.

The research was carried out within the state assignments: No.0708-2020 - 0001 (Moscow State University of Geodesy and Cartography) and AAAA - A19 - 119040990079 - 3 No. 0147 - 2019 - 0004 (Water Problem Institute of Russian Academy of Sciences) of the Ministry of Education and Science of Russia. 